
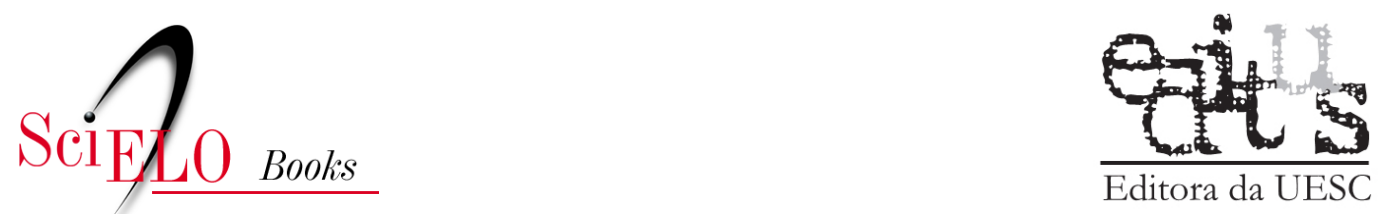

\title{
Representação social e terceira idade aspectos e (novas) perspectivas
}

\author{
Amanda Dias Vieira \\ Wagner Augusto Hundertmarck Pompéo
}

\section{SciELO Books / SciELO Livros / SciELO Libros}

VIEIRA, A. D., and POMPÉO, W. A. H. Representação social e terceira idade: aspectos e (novas) perspectivas. In: D'ALENCAR, R. S., ed. A representação social na construção da velhice [online]. Ilhéus, BA: EDITUS. 2017, pp. 135145. ISBN: 978-85-7455-486-0. https://doi.org/10.7476/9788574554860.0007.

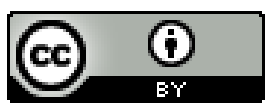

All the contents of this work, except where otherwise noted, is licensed under a Creative Commons Attribution 4.0 International license.

Todo o conteúdo deste trabalho, exceto quando houver ressalva, é publicado sob a licença Creative Commons Atribição 4.0.

Todo el contenido de esta obra, excepto donde se indique lo contrario, está bajo licencia de la licencia Creative Commons Reconocimento 4.0. 


\title{
REPRESENTAÇÃO SOCIAL E TERCEIRA IDADE: ASPECTOS E (NOVAS) PERSPECTIVAS
}

\author{
Amanda Dias Vieira \\ Wagner Augusto Hundertmarck Pompéo
}

\section{Introdução}

Recentemente, o Brasil despertou para o estudo e aprofundamento das questões atinentes à pessoa idosa. Dentre outras razões, isso se deu, sobretudo, pelo aumento significativo dessa população, o que indica que os índices de desenvolvimento humano do país estão melhores do que em um passado recente.

Com isso, faz-se necessária a análise de como, quando e de que forma se dá a representatividade social dos idosos nos dias de hoje. Esse é, basicamente, o objetivo geral do presente trabalho, com o qual se pretende demonstrar a grande transformação que o tratamento com esse público teve no decorrer dos últimos anos.

Para isso, o trabalho foi dividido em três capítulos. O primeiro abordará a terceira idade em números, trazendo, basicamente, dados estatísticos extraídos do Instituto Brasileiro de Geografia e Estatística - IBGE. O segundo alude, de modo geral, como se dava a representação social dos idosos no passado, trazendo seus principais aspectos. O terceiro, por sua vez, ocupa-se de retratar 
como essa representatividade ocorre no presente momento, bem como reflete as novas perspectivas para o futuro.

Assim, foi desenvolvido por meio essencialmente teórico, sendo dado destaque às pesquisas e dados oficiais provenientes do IBGE. Além das referências indicadas, a pesquisa, como se verá ao longo do texto, mostra-se em relação aos objetivos dialética e quanto ao método de abordagem dedutiva.

\section{Terceira idade em números}

O Brasil é o $5^{\circ}$ (quinto) país mais extenso do mundo, contando com uma área de $8.515 .767,049 \mathrm{~km}^{2}$, o que leva o país a ser, coincidentemente, o $5^{\circ}$ (quinto) mais populoso do globo, possuindo, segundo projeção do Instituto Brasileiro de Geografia e Estatística - IBGE, atualmente, 206.276.616 (duzentos e seis milhões, duzentos e setenta e seis mil, seiscentas e dezesseis) ${ }^{1}$ pessoas em sua extensão territorial (IBGE, 2016).

Um dos requisitos mais importantes a serem considerados para que se possa auferir que um país é realmente desenvolvido em relação aos demais é o número de idosos em sua população. O fato de existirem muitas pessoas idosas em um país é um indicativo claramente positivo. Isso se deve ao fato de que o mesmo, possivelmente, vai ao encontro do que é considerado para que se tenha uma vida saudável, digna e longínqua, de modo que a perspectiva de viver passa a ser maior e, consequentemente, o nível de desenvolvimento do local também.

Conforme artigo $1^{\circ}$ (primeiro) do Estatuto do Idoso do Brasil, Lei n. ${ }^{\circ} 10.741$ de 2003, é considerado idoso, e, portanto, para quem são destinados e assegurados os direitos

1 População brasileira em 10 de agosto de 2016, às 10 h58. 
previstos em referida lei, quem contar com idade igual ou superior a 60 (sessenta) anos (ESTATUTO DO IDOSO, 2003). A partir dessa constatação é que se pode começar a discutir os números em relação à terceira idade.

Segundo senso do IBGE de 2011, pessoas com mais de 60 (sessenta) anos somavam 23,5 milhões de brasileiros, sendo que 10 (dez) anos antes, em 1991, o número de idosos era $50 \%$ (cinquenta por cento) menor do que o de 2011 , totalizando 10,7 milhões de pessoas. Isso significa um crescimento de 55\% (cinquenta e cinco por cento) em 10 (dez) anos, uma representação de aproximadamente $12 \%$ (doze por cento) da população brasileira (SECRETARIA DE DIREITOS HUMANOS, 2016).

De acordo com a Tábua Completa de Mortalidade do IBGE, do ano de 2014, a expectativa de vida dos brasileiros aumentou, em média, para 75,2 anos de idade. $\mathrm{O}$ estudo aponta que a expectativa de vida das mulheres é maior, sendo de aproximadamente 78,8 anos, enquanto dos homens é de 71,6 anos. A análise refere que Santa Catarina foi o estado que alcançou a maior expectativa de vida, chegando aos 78,4 anos. Em contraponto, o estado com menor alcance foi o Maranhão, com 70 anos de idade (PORTAL BRASIL, 2015).

Como se pode notar pelo já evidenciado até o presente momento, a expectativa de vida dos brasileiros tende a crescer com o passar dos anos. Ratificando essa conclusão inicial, dados sociodemográficos e de saúde do IBGE, do ano de 2009, demonstram que essa expectativa pode chegar a uma média de 81,3 anos em 2050 (BRASIL IDOSO, 2016).

Cumpre destacar, por fim, que, somente agora, na última década, o Brasil despertou para a nova realidade do envelhecimento majoritário da população, bem como o valor disso para o bem-estar da mesma como um todo, passando a reconhecer a importância de estudar o envelhecimento humano. É nesse sentido que se enquadra a representação social da população idosa, a qual será abordada nos próximos tópicos. 


\section{Representação social no passado}

O idoso sempre foi visto, tradicionalmente, como alguém limitado, quase deficiente (os que não o eram), e sem nenhuma perspectiva de futuro. Alguém que não era, e nem deveria ser, incluído socialmente, sendo visto, inclusive, como problema e incômodo para muitas famílias, o que levava (e ainda leva) idosos saudáveis e doentes ao completo abandono dentro de seus próprios lares ou em casas especializadas para idosos, popularmente conhecidas como asilos.

Além disso, os idosos acabavam não sendo objeto de proteção especial alguma, nem mesmo destinatários de politicas públicas ou outras formas que proporcionassem uma vida melhor, bem como uma manutenção digna da mesma. Na ampla maioria das vezes, eles não possuiam voz nem vez, não eram respeitadas ou sequer ouvidas as suas vontades, nem dada à mínima autonomia necessária para que realizassem suas próprias escolhas.

Prova disso são os dados trazidos no primeiro tópico a respeito da expectativa de vida dos brasileiros. Se atualmente esse número é alto e vem crescendo, no passado era bem baixo. Em 2014, como mencionado, a expectativa era de 75,2 anos. Em 1984, 30 anos antes, era de 64,15 anos, o que demonstra um aumento de, aproximadamente, 11 anos de vida (IBGE, 2016). Isso se deve ao fato de, em absoluto, a consideração em relação à pessoa idosa ter aumentado exponencialmente, não somente no que diz respeito a sua autonomia de vontade, mas também no que diz respeito aos seus direitos estarem, agora, assegurados por lei especial (o que se verá no tópico seguinte), há uma maior inclusão social e, assim, maiores perspectivas de um futuro digno. Isso já acontece no presente momento do Brasil, bem como nas projeções existentes para o futuro. 


\section{Representação social no presente e no futuro}

Para que se comece a pensar em representação social, e de como isso reflete na população idosa atualmente, se faz necessário o esclarecimento do que é cidadania, pois uma está diretamente ligada à outra. A Secretaria de Direitos Humanos e Cidadania do Estado do Paraná elucida que:

Exercer a cidadania plena é ter direitos civis, políticos e sociais. Expressa a igualdade dos indivíduos perante a lei, pertencendo a uma sociedade organizada. É a qualidade do cidadão de poder exercer o conjunto de direitos e liberdades políticas, socioeconômicas de seu país, estando sujeito a deveres que lhe são impostos. Relaciona-se, portanto, com a participação consciente e responsável do indivíduo na sociedade, zelando para que seus direitos não sejam violados (DEPARTAMENTO DE DIREITOS HUMANOS E CIDADANIA, 2016).

Já a representação social, mais complexa, mas não de difícil, compreensão, pode ser elucidada como sendo "[...] produzida na construção do cotidiano de cada indivíduo, a teoria das Representações Sociais tenta entender as lutas, batalhas, espaços, formas de comunicação desses indivíduos e o que eles produzem de saberes no e pelo cotidiano" (PORTAL EDUCAÇÃO, 2013).

Alcançar referida cidadania - na velhice - não é, e nem está longe de ser, mera utopia. Para que seja obtida é necessário que diversas medidas sejam tomadas, como mais políticas públicas, mais inclusão e, principalmente, representação social, mais autonomia para o idoso, bem como maior crédito e visibilidade na sociedade e, ainda, uma maior proteção por parte do Estado através de leis especiais, por exemplo.

Hoje a realidade já é outra e exemplo disso são práticas que antes eram inimagináveis para pessoas acima 
de 60 (sessenta) anos e que hoje estão crescendo em todo o país. Uma dessas novas práticas é o estudo universitário. Atualmente, além dos cursinhos básicos oferecidos em muitas instituições de caridade, existem as Universidades ou Faculdades da Maturidade.

A Faculdade da Maturidade oferecida pela Faculdade Municipal de Palhoça, na Grande Florianópolis (DIÁRIO CATARINENSE, 2014), a Universidade Aberta da Maturidade, da Universidade Federal do Paraná (UNIVERSIDADE ABERTA DA MATURIDADE, 2016), e a Universidade da Maturidade, extensão da Universidade de Brasilia (UNIVERSIDADE DA MATURIDADE DISTRITO FEDERAL, 2016), são exemplos de cursos ofertados a pessoas acima de 50, 55 e 45 anos, respectivamente, que trazem disciplinas que são áreas de interesse das pessoas idosas, como economia, educação física, empreendedorismo, entre outras.

O conhecimento de alguma dessas searas, pela pessoa idosa, além de benéfico para a saúde mental, mantendo ativas as funções do cérebro, é de grande valia para o dia a dia, como o empreendedorismo, que traz uma nova visão de como estabelecer e manter um negócio, o que pode contribuir para aqueles que sempre almejaram ter o seu próprio, bem como aqueles que já o têm, mas possuíam dificuldades de fazer sua manutenção. Isso traz novas perspectivas de futuro, e não a mera espera pela morte, como se via antigamente.

Outra prática que tem aumentado cada vez mais no mundo, e não poderia deixar de ser diferente na terceira idade, é o acesso à internet e o consequente uso das novas tecnologias, como smartphones, tablets, notebooks, etc. Uma pesquisa realizada nas regiões de Ribeirão Preto e Olímpia, São Paulo, com 100 pessoas contando com mais de 65 (sessenta e cinco) anos de idade constatou que as pessoas idosas, em sua grande maioria, aceitam bem as novas tecnologias (UNIVERSIDADE DE SÃO PAULO, 2013). 
Mais do que aceitarem, os idosos querem que essas novas tecnologias façam parte de sua rotina. Não é à toa que muitos cursos de informática são ofertados a esse público, o que contribui para que percam o medo de utilizar a internet e passem a fazer parte dessa realidade. O uso da rede mundial de computadores faz com que a população idosa fique mais autônoma, possa conversar com parentes distantes, faça novos amigos e se sinta mais incluída e representada na sociedade (ESTADÃO, 2010).

Talvez o maior e mais significativo avanço desde aquele velho e ultrapassado paradigma de idoso limitado e sem perspectivas tenha sido a promulgação da Lei n. ${ }^{\circ} 10.741$, de $1^{\circ}$ de outubro de 2003, conhecido como Estatuto do Idoso. A referida lei especial, destinada fundamentalmente a todas as pessoas maiores de 60 (sessenta) anos de idade, conta com 118 (cento e dezoito) artigos que, resumidamente, asseguram direitos essenciais à pessoa idosa.

O Estatuto garante o direito à vida, à liberdade, ao respeito, à dignidade, à prestação de alimentos, à saúde, à educação, à cultura, ao esporte, ao lazer, à profissionalização, ao trabalho, à habitação, ao transporte. Também dispõe sobre a previdência e a assistência social, as medidas de proteção acerca da política de atendimento ao idoso e suas entidades, o respeito do acesso à justiça e, por fim, os crimes relativos à pessoa idosa.

A Organização das Nações Unidas no Brasil traz um posicionamento bem claro quanto à população idosa:

O mundo está no centro de uma transição do processo demográfico única e irreversivel que irá resultar em populações mais velhas em todos os lugares. [...]

As pessoas mais velhas têm, cada vez mais, sido vistas como contribuintes para o desenvolvimento, e suas habilidades para melhorar suas vidas e suas sociedades devem ser transformadas em politicas e programas em todos os niveis (ORGANIZAÇÃO DAS NAÇÕES UNIDAS, 2016). 
Isto é, a partir dessa declaração da ONU Brasil e com o que foi trazido até o presente momento, resta evidenciado que com a garantia e, evidentemente, com a efetivação de uma vida com muito mais qualidade, seja a partir dos direitos assegurados por lei especial, seja por políticas públicas efetivas, fatos que acabam por propiciar mais autonomia aos idosos, os mesmos restam representados, como visto, nas mais distintas áreas da sociedade.

Com isso, importa dizer e destacar que houve a inversão completa daquele antigo paradigma trazido no primeiro tópico do texto, o qual constatava que o idoso era visto como limitado, sem perspectivas de um futuro melhor, não sendo incluído socialmente e não possuindo nenhuma legislação específica a seu respeito. Hoje, o idoso tem o direito de levar uma vida com qualidade, autonomia e projeções para o futuro.

\section{Considerações finais}

Depreendendo-se de todo o explanado até aqui, podese chegar a algumas conclusões acerca do tema, o qual envolve, basicamente, em que medida se dá a representação social dos idosos no Brasil. Foram abordadas ainda questões atinentes aos seus aspectos mais importantes e, reflexamente, a respeito das novas perspectivas sobre a matéria.

Com o capítulo primeiro pode-se constatar claramente a importância das pesquisas estatísticas e de se obterem dados formais como fonte primordial, pois a partir da verificação de que o número de pessoas na terceira idade tem crescido exponencialmente, pode-se auferir que o Brasil tem se desenvolvido melhor e cada vez mais. A partir do momento em que um número mais expressivo de idosos figura na pirâmide do desenvolvimento humano, importa destacar que mais qualidade de vida a esses brasileiros está sendo proporcionada, sobretudo em idades mais avançadas, mas contando, agora, com mais saúde e dignidade. 
Em relação ao capítulo dois, foi oportunizado relembrar como eram vistos os idosos em um passado não tão distante. O paradigma era de que os mesmos fossem limitados e sem perspectivas de futuro, o que acabava tornando-se realidade, pois as oportunidades acabavam sendo escassas e em menores proporções do que para as outras camadas da população, tornando-os, assim, limitados em relação a tudo que poderiam viver, vivenciar e ainda produzir na sociedade, restando sem ou com pouquíssima representação social.

O terceiro, e último capítulo, teve o intuito de demonstrar de que maneira e proporção a representação social da população idosa acontece nos dias de hoje, podendo-se auferir, claramente, que a tendência é a de que essa representação aumente mais a partir da nova realidade brasileira. Hoje os idosos têm inúmeras oportunidades que antes não possuíam. Atualmente, são ofertadas práticas como as Faculdades da Maturidade, trazendo cursos que sejam de áreas de seus interesses, fazendo com que a saúde mental não se estagne no tempo. Tem-se observado, também, o maior uso das redes, o que faz com que os idosos se sintam e se tornem mais autônomos em relação ao que pretendem e querem fazer. E, ainda, a criação e posterior efetivação dos direitos assegurados por meio do Estatuto do Idoso, o qual traz diversas garantias às pessoas acima de 65 (sessenta e cinco) anos de idade.

Por conseguinte, após serem exauridos todos os pontos abordados ao longo do trabalho, conclui-se que é estritamente necessário que se dê continuidade a esse cenário de transformação. Afinal, muito ainda precisa ser lapidado e aprimorado para que os idosos possuam mais politicas públicas, uma maior efetivação dos direitos que lhe são assegurados no Estatuto do Idoso e mais formas e práticas que os representem na sociedade para que sua qualidade de vida continue a crescer e, assim, seja literal o sentido de colocá-los na "melhor idade". 


\section{Referências}

ALENCAR, Bruna de. Pesquisa tenta entender a complicada relação entre idosos e tecnologia. Universidade de São Paulo. Disponivel em: <http://www5.usp.br/35129/pesquisa-tenta-entender-a-complicada-relacao-entre-idosos-e-tecnologia/>. Acesso em: 11 ago. 2016.

BRASIL IDOSO. Disponível em: <https://brasilidoso.wordpress.com/estatisticas/crescimento da população idosa no mundo/\#jp-carousel-146>. Acesso em: 10 ago. 2016.

BRASIL. Estatuto do Idoso, Lei n. ${ }^{\circ} 10.741$, de $1^{\circ}$ de outubro de 2003. Brasília, DF: Secretaria Especial dos Direitos Humanos, 2003.

DEPARTAMENTO DE DIREITOS HUMANOS E CIDADANIA. O que é ser cidadão?. Disponivel em: <http://www.dedihc. pr.gov.br/modules / conteudo/conteudo.php?conteudo $=8>$. Acesso em: 12 ago. 2016.

IBGE. Área Territorial Brasileira. Disponivel em: <http:// www.ibge.gov.br/home/geociencias/cartografia/default_territ_area.shtm>. Acesso em: 10 ago. 2016.

- Projeção da população do Brasil e das Unidades da Federação. Disponivel em: <http://www.ibge.gov.br/apps/ populacao/projecao/>. Acesso em: 10 ago. 2016.

IWASSO, Simone. Tecnologia ajuda a integrar idosos. Estadão, São Paulo, 2010. Disponível em: <http://www.estadao. com.br/noticias / geral, tecnologia-ajuda-a-integrar-idosos,493212>. Acesso em: 11 ago. 2016.

LUMINI, Milena. Faculdade da Maturidade leva terceira idade de volta aos estudos. Diário Catarinense, Florianópolis, 2014. Disponivel em: <http://dc.clicrbs.com.br/sc/noticias/noticia/2014/10/faculdade-da-maturidade-leva-terceira-idade-de-volta-aos-estudos-4621629.html>. Acesso em: 11 ago. 2016. 
ORGANIZAÇÃO DAS NAÇÕES UNIDAS. A ONU e as pessoas idosas. Disponivel em: <https://nacoesunidas.org/acao/ pessoas-idosas/>. Acesso em: 11 ago. 2016.

PORTAL BRASIL. Expectativa de vida do brasileiro sobre para 75,2 anos. Disponivel em: <http://www.brasil.gov.br/ cidadania-e-justica/2015/11/expectativa-de-vida-do-brasileiro-sobe-para-75-2-anos>. Acesso em: 10 ago. 2016.

PORTAL EDUCAÇÃO. Teoria das representações sociais. Disponivel em: <http://www.portaleducacao.com.br/psicologia/artigos/32194/teoria-das-representacoes-sociais >. Acesso em: 11 ago. 2016.

SECRETARIA DE DIREITOS HUMANOS. Dados sobre o envelhecimento no Brasil. Disponivel em: <http://www.sdh. gov.br/assuntos/pessoa-idosa/dados-estatisticos/DadossobreoenvelhecimentonoBrasil.pdf $>$. Acesso em Acesso em: 10 ago. 2016.

UNIVERSIDADE ABERTA DA MATURIDADE. Disponivel em: <http://www.uam.ufpr.br/>. Acesso em: Acesso em: 11 ago. 2016.

UNIVERSIDADE DA MATURIDADE DISTRITO FEDERAL. Disponivel em: <http://umadf.com>. Acesso em: 10 ago. 2016. 